\title{
Balanced Chromosomal Translocation
}

National Cancer Institute

\section{Source}

National Cancer Institute. Balanced Chromosomal Translocation. NCI Thesaurus. Code C6822.

Interchanges of genetic material among different chromosomes following the breaking off of pieces of chromosomes such that the total chromosome composition may still contain all of the genetic material.Balanced Chromosomal Rearrangement. 